\title{
A study of the Activities and Impact of the Asian Productivity Organisation (APO)
}

Purpose: The purpose of this study is to investigate the activities of the Asian Productivity Organisation (APO). The study identifies the various roles and activities of the APO and evaluates how well it performs in these roles. The study also investigates the impacts of the APO on the productivity initiatives of National Productivity Organisations (NPOs) in sixteen Asian countries. These productivity initiatives are important in enhancing productivity performance and national competitiveness in the countries of interest.

Design/methodology/approach: The study collects data from stakeholders in the NPOs in sixteen countries. A likert-scale questionnaire was used to collect data from two types of respondents - NPO CEOs and NPO professional/technical staff. Data was analysed by comparing the responses across the participating countries.

Findings: The result shows that there was general satisfaction with the mission, vision, and strategic direction of the APO. With respect to the operational performance of the organisation, the study showed that there were some differences in perception of the performance of the APO although the overall perception was positive.

Practical Implications: The study provides insights to the top management of the APO with regards to deciding on the future direction of the organisation and, in particular, the ways in which it understands and supports the varied requirements of the different NPOs.

Originality/value: Organisations such as the APO dedicate significant resources into supporting NPOs, and by extension productivity-related commercial operations, in several countries. It is important to understand how these services are perceived and experienced in these countries and a definitive study to examine this has not previously been carried out.

Keywords: Asia, Asian Productivity Organisation, APO, Productivity, National Productivity Organisation 


\section{A study of the Activities and Impact of the Asian Productivity Organisation (APO)}

\section{Introduction}

The growth and expansion of Asian domestic markets coupled with the preference of many western organisations to outsource their manufacturing activities to Asian manufacturers has led to the rapid growth of manufacturing in Asian countries. Alongside the traditional stalwarts such as Japan, Singapore and South Korea, Asia is characterised by rapidly industrialising nations (e.g. India and China) as well as 'frontier' nations such as Vietnam and Laos. The success that these countries achieve will, to a significant extent, be determined by the level of productivity of their organisations. Consequently, national and international organisations that are charged with promoting and encouraging productivity can, potentially, be pivotal players in the outcomes achieved by either individual organisations and/or countries. The predominant organisation in Asia for promoting and encouraging productivity is the pan-national Asia Productivity Organisation (APO).

This study examines the activities of the APO and the impact that these activities have had on NPOs and Asian firms. It is based on the views of chief executives and directors of NPO organisations from 16 Asian countries. The study seeks to identify the level of satisfaction with the various initiatives and services the APO provides as well as its strategic positioning. The countries examined in this study are Bangladesh, Cambodia, Republic of China, Fiji, India, Indonesia, Iran, Lao, Malaysia, Mongolia, Nepal, Pakistan, Philippines, Sri Lanka, Thailand and Vietnam. Singapore, Korea and Japan decided not to participate as they considered that their own NPOs were already highly advanced and largely provided a role assisting other countries through the APO's services rather than benefiting directly from them.

The motivation for the study is three-fold. Firstly, despite the firmly established footprints of the APO and its associated National Productivity Organisations (NPOs) in Asia, there is yet to be a comprehensive study to examine the perceptions of Asian organisations about its impact and activities. Secondly, while the APO is responsible for setting pan-national strategic initiatives to encourage productivity, there is no study that has examined the perceptions of the NPOs from different countries about the APO's activities. Thirdly, the findings from the study can provide information that can inform future strategic initiatives and activities of the APO.

The importance of this study is underpinned by the APO's commitment to maximise productivity in Asia. The study ultimately aims to assist the APO in leading and supporting NPOs on improving productivity across Asia.

\section{The Asian Productivity Organisation}

The APO is a regional intergovernmental non-profit organisation. It was established on 11 May 1961. APO membership is open to countries in Asia and the Pacific who are members of the United Nations Economic and Social Commission for Asia and the Pacific. Current membership comprises Bangladesh, Cambodia, the Republic of China, Fiji, Hong Kong (although not an active member since it's handover to China in 1997), India, Indonesia, the Islamic Republic of Iran, Japan, the Republic of 
Korea, Lao PDR, Malaysia, Mongolia, Nepal, Pakistan, the Philippines, Singapore, Sri Lanka, Thailand, and Vietnam. These countries pledge to assist each other in their productivity drives in a spirit of mutual cooperation by sharing knowledge, information, and experience (APO, 2015). APO projects and programmes from 1990 to 2010 were based on the five thrust areas as follows: (1) knowledge management, (2) green productivity, (3) strengthening of small to medium sized enterprises (SMEs), (4) integrated community development, and (5) development of NPOs.

\section{Literature Review}

Productivity has been studied extensively in academic literature. Mathur et al. (2012) described productivity as a measure of the relationship between inputs (for example, capital, material labour) and outputs (goods and services delivered). However, this simplistic view belies the complexities that underpin how productivity has been viewed and defined. For example, Mohanty (1988) identified 12 different definitions of productivity and suggested they varied in perspective from micro to macro-level and from welfare to operational efficiency orientation. Teng (2014), on the other hand, considered productivity from a measurement perspective and in so doing, delineated productivity into general productivity, capital productivity and facilities productivity. Irrespective of the perspective or definition chosen, what is not in doubt is that low productivity is undesirable while high productivity should be embraced (Burgess, 1990).

There are several reasons why productivity is seen as important. At a macro level growth in a nation's economy has been linked with growth in productivity (Burgess, 1990). Perhaps more importantly, productivity has been linked with quality of life. According to Peskircioglu (2008), gains

in productivity in all sectors can make a major contribution to raising living standards while Mohanty (1988) described productivity as the key to "enhancing the quality of life". Peskircioglu (2008) proposed that increases in productivity can underpin an improvement in international competitiveness of a country. Similar views were stressed by Mathur et al. (2012) when they associated improved productivity with increased competitiveness and the ability to operate in a global marketplace.

\section{Involvement of Governments}

The impact of productivity on the economy, international competitiveness and the quality of life is a key reason why governments have taken an active interest and role in enhancing productivity. A study by Kocer (2014) found that governments in countries as diverse as Australia, Slovakia, Canada, Finland and France have taken active roles in supporting productivity improvement. The interventions of governments have come in several ways including the enactment of labour laws (Australia), skills improvement initiatives (Britain) and the launching of national productivity programmes in Finland and Slovakia. Governments have also supported productivity improvements by promoting awareness of the gains of productivity while also providing financial incentives for programmes that aim to improve employee skills (Kocer, 2014). The involvement of government in productivity initiatives is often at a national, regional and local government level (Savery, 1998).

While Kocer's study focused primarily on developed economies, other studies have been more interested in the roles that governments in developing economies play in enhancing productivity. 
Shurchuluu (2002) stressed that developing countries need to raise their productivity quickly if they are to compete on the world stage and that governments have an important role to play in enhancing such productivity improvement. This includes the provision of infrastructure and development of education systems. With particular reference to Asia, Sarwar et al. (2012) decried the poor levels of productivity in Pakistan while noting that governments in South East Asia have taken a more active role in promoting industrial growth in contrast to western governments. The more active role played by governments in South East Asia may be as a result of the need to enable organisations in the region to rapidly raise their levels of productivity and competitiveness in an environment of outsourcing as well as national imperatives to improve the quality of life of their citizens.

\section{NPOs and the APO}

One of the manifestations of governmental interest in productivity gains has been the establishment of national productivity organisations. In Japan, the Japan Productivity Centre has been active for decades in the dissemination of productivity related information (Stainer, 1995) while India's National Productivity Council provides training to help improve employee skills (Jain and Ahuja, 2012). In Turkey, the Turkish Productivity Improvement Centre has led Productivity Improvement Project in Provinces for which beneficiary organisations do not have to make a direct financial contribution (Peskircioglu, 2008). The National Productivity Board in Singapore, which evolved into SPRING Singapore, led many important initiatives to change the attitudes of employees in an effort to support productivity improvement (Sakurai, 1986). In Slovakia, the productivity improvement drive is led by the Slovak Productivity Centre. Indeed, most countries have an organisation or a number of organisations responsible for leading productivity initiatives within their country. In some cases these organisations are called National Productivity Organisations or similar if their sole focus is productivity improvement. In other cases their name may reflect a wider role particularly if their responsibilities are broader than productivity improvement. For example, in New Zealand the organisation leading productivity initiatives is called Trade and Enterprise New Zealand whose main purpose is to assist businesses to succeed internationally through assistance in exporting, marketing and securing investment in addition to productivity improvement.

It is evident that NPOs play a key role in supporting and enhancing productivity improvement. While most NPOs get significant support from their respective government, many NPOs are members of and gain support from Trans-national productivity organisations. In Europe, there is a European Association of National Productivity Centres (Kocer, 2014), while in Asia, it is the APO. The APO has been credited with leading many ambitious initiatives. For example, according to Ho (2010), the APO in conjunction with its affiliated NPOs promoted the 5 S methodology in the 1980s. The APO has also been credited as being a leader in integrating sustainability with productivity by introducing the concept of green productivity (Tuttle and Heap, 2007). Recently the APO has created three Centres of Excellence to become a thought leader in business excellence (launched 2008), green productivity (launched 2011) and public sector productivity (launched 2015).

However, despite the long establishment of the APO and its leadership of many initiatives aimed at improving productivity by supporting NPOs, little is known about the relationships between the APO and its associated NPOs work in practice outside of its membership. Similarly, there has not been a 
comprehensive study to understand the perceptions of the various Asian NPOs about the benefits they gain from the APOs activities. Such information is important to enable the APO to improve its effectiveness particularly as different NPOs are at different levels of evolution and development and, consequently, their needs would be different. Without carrying out a comprehensive study of perceptions of Asian NPOs, it is difficult for the APO to target future strategies and activities accurately to support its NPO members.

\section{Research Objectives}

Based on the interests of the APO and NPOs, the research objectives for the study are now presented as follows:

- RO1: To identify NPO perceptions of the Mission, Vision and Strategy of the APO,

- RO2: To investigate perceptions of the Key Roles of the APO and compare these with its perceived levels of performance,

- RO3: To identify levels of satisfaction of NPOs with APO operational performance,

- RO4: To identify areas for improvement in terms of APO support for NPOs.

\section{Research Methodology}

The research methodology used was a questionnaire survey. The project commenced with the chief expert devising the research processes with input from the APO. This was followed by a coordination meeting involving all National Experts to finalise the research processes and the design of questionnaires. Sixteen national experts ${ }^{1}$ were assigned to collect data in their respective countries. The national experts were from: Bangladesh, Cambodia, The Republic of China, Fiji, India, Indonesia, Iran, Lao, Malaysia, Mongolia, Nepal, Pakistan, Philippines, Sri Lanka, Thailand and Vietnam.

To ensure consistency of data for comparison and aggregation purposes, a National Expert Survey and two Stakeholder Surveys were developed with clear guidelines on how the data should be collected. The National Expert Survey consisted of five main sections: (1) Profile of the country, (2) NPO's strategy, systems and services, (3) NPO's Performance Results, (4) Strengths, Weaknesses, Opportunities and Threats (SWOT) analysis, and (5) APO's strategy and assistance. This paper focuses on the findings of Section 5 (APO's strategy and assistance). Table 1 summarises how the questions from the Stakeholder Surveys were linked to Section 5 of the National Expert Survey. The Stakeholder Surveys were designed so that they could be sent by email or posted to respondents for completion or used as a basis for a one to one structured interview whereby the National Expert could ask the respondents the questions and record their responses. The Stakeholder Surveys and the number of surveys that were targeted for completion are described in Table 2. 
Table 1: Links of questions in Section 5 of National Expert Survey with Stakeholder Surveys

\begin{tabular}{|l|c|c|c|}
\hline \multicolumn{2}{|c|}{} & \multicolumn{2}{|c|}{$\begin{array}{c}\text { STAKEHOLDER SURVEY } \\
\text { (SS) }\end{array}$} \\
\cline { 2 - 4 } & $\begin{array}{c}\text { NPO CEO / } \\
\text { DIRECTORS }\end{array}$ & NPO STAFF \\
\hline CEO/directors assessment of the APO's vision & $5.1 \mathrm{a}$ & $4.1 \mathrm{a}$ & \\
\hline Suggested changes to vision & $5.1 \mathrm{~b}$ & $4.1 \mathrm{~b}$ & \\
\hline CEO/director's assessment of the APO's mission & $5.2 \mathrm{a}$ & $4.2 \mathrm{a}$ & \\
\hline Suggested changes to mission & $5.2 \mathrm{~b}$ & $4.2 \mathrm{~b}$ & \\
\hline CEO/director's assessment of the APO's strategic direction & $5.3 \mathrm{a}$ & $4.3 \mathrm{a}$ & \\
\hline Suggested changes to strategic direction & $5.3 \mathrm{~b}$ & $4.3 \mathrm{~b}$ & \\
\hline CEO/director's assessment of the APO's key roles & $5.4 \mathrm{a}$ & $4.4 \mathrm{a}$ & \\
\hline Suggested changed to key roles & $5.4 \mathrm{~b}$ & $4.4 \mathrm{~b}$ & \\
\hline $\begin{array}{l}\text { CEO/directors assessment of the current performance of the } \\
\text { APO }\end{array}$ & & & \\
\hline CEO/directors/staff assessment of impact of projects/events & 5.5 & 4.5 & \\
\hline $\begin{array}{l}\text { CEO/directors/staff understanding of APO role and its } \\
\text { programmes }\end{array}$ & 5.6 & 4.6 & $2.1 \mathrm{~b}$ \\
\hline $\begin{array}{l}\text { Percentage of CEO/directors and staff that have visited the } \\
\text { APO website in the last 2 months? }\end{array}$ & 5.7 & 4.7 & 2.2 \\
\hline $\begin{array}{l}\text { Percentage of CEO/directors and staff that have read an APO } \\
\text { Newsletter in the last 2 months? }\end{array}$ & 5.9 & 4.9 & \\
\hline $\begin{array}{l}\text { What is the CEO/directors level of satisfaction with the APO } \\
\text { Secretariat in the following areas? }\end{array}$ & $5.10 \mathrm{a}$ & $4.10 \mathrm{a}$ & \\
\hline $\begin{array}{l}\text { Suggested changes/comments for areas in need of } \\
\text { improvement }\end{array}$ & $5.10 \mathrm{~b}$ & $4.10 \mathrm{~b}$ & \\
\hline $\begin{array}{l}\text { Indicate the impact of these APO activities on your NPO's } \\
\text { productivity initiatives: }\end{array}$ & $5.11 \mathrm{a}$ & $4.11 \mathrm{a}$ & \\
\hline $\begin{array}{l}\text { Suggested changes/comments for areas in need of } \\
\text { improvement }\end{array}$ & $5.11 \mathrm{~b}$ & $4.11 \mathrm{~b}$ & \\
\hline Level of satisfaction with being a member of the APO & $5.12 \mathrm{a}$ & $4.12 \mathrm{a}$ & \\
\hline Comments & $5.12 \mathrm{~b}$ & $4.12 \mathrm{~b}$ & \\
\hline
\end{tabular}

Table 2: Types of stakeholder surveys and minimum number of surveys to be completed

\begin{tabular}{|l|l|}
\hline \multicolumn{1}{|c|}{ Stakeholder Surveys } & \multicolumn{1}{c|}{ Minimum number of surveys to be completed } \\
\hline NPO CEO/Directors & $\begin{array}{l}\text { At least } 75 \% \text { of CEO/Directors should complete } \\
\text { this survey. }\end{array}$ \\
\hline NPO Staff (Professional \& Technical only) & $\begin{array}{l}\text { At least } 20 \text { surveys completed in total or at least } \\
50 \% \text { of staff should complete this survey }\end{array}$ \\
& \\
\hline
\end{tabular}

Information gleaned from the Stakeholder Surveys assisted the National Experts to complete the National Expert Survey which was then sent to the Chief Expert for analysis. The National Expert was 
also asked to review the NPO's strategy, annual report and performance reports. Of prime importance was that the National Experts Survey was completed accurately, bearing in mind potential translation issues, and represented the views of NPO stakeholders rather than the National Experts' personal views. To check project progress and the accuracy of survey completion there was regular reporting between the National Experts and the Chief Expert.

\section{Findings}

The findings from the study are presented in this section. They are presented in three subsections which are motivated by the research objectives of the study. A discussion of these findings is presented in the next section.

\section{Perceptions of the Mission, Vision and Strategy of the APO}

The mission of the APO is stated as "contribute to the sustainable socioeconomic development of Asia and the Pacific through enhancing productivity" while its vision is "to be the leading international organization on productivity enhancement, enabling APO economies to be more productive and competitive by 2020". Figure 1 shows that, overall, the majority of countries either agreed or strongly agreed with the mission and vision of the APO. The overall mean for both the mission and vision was 5.3 (Therefore the mean falls between Agree which was indicated by a 5 and Strongly Agree which was indicated as a 6).

Figure 2 presents findings relating to the strategy of the APO. In particular, three strategic directions were examined. The first of these was the support provided to NPOs and the promotion of the development of SMEs and communities. The second was the APO's strategic direction to catalyse innovation-led productivity growth while the third was the promotion of green productivity. The findings show that, overall, most NPOs agreed or strongly agreed with all three strategic directions with mean values of 5.6,5.3 and 5.4 respectively (therefore the means fall between Agree which was indicated by a 5 and Strongly Agree which was indicated as a 6). Four countries - Country 1 , Country 5, Country 8 and Country 13 strongly agreed with all three strategic directions. In contrast, Country 12 had the lowest overall perception score as it neither agreed nor disagreed with the APO's strategic direction as a catalyst for innovation-led productivity growth while agreeing less strongly with the other two strategic directions than other countries.

\section{Place Figures 1 and 2}

\section{Assessment of the APO's key roles and current performance in these roles}

The APO performs five key strategic roles - a think tank, catalyst, regional adviser, institution builder and a clearing house for productivity information. Overall the CEOs/directors from the NPOs agreed or strongly agreed with each of the roles of the NPO. The average scores were 5.5 (think tank), 5.4 (catalyst), 5.4 (regional adviser), 5.6 (institution builder) and 5.3 (clearing house). However, with respect to the current performance of the NPO in these roles, average scores were lower with none 
of the scores in the very good - excellent range. Rather, the average score were in the good - very good range as follows: 4.4 (think tank), 4.6(catalyst), 4.1 (regional adviser), 4.6 (institution builder) and 4.6 (clearing house). The results are shown in figure 3.

\section{Place Figure 3}

While the findings in figure 3 present an aggregated view, if these findings are disaggregated and viewed by each role and by each respondent country, a much more complex picture is presented. Figures $4-8$ below present a disaggregated view on the perception of the roles and associated performance of the APO. While for each role, almost every respondent agreed or strongly agreed with the APOs guardianship of the role, the perceptions about current levels of performance were less unanimous. With respect to its performance as a think tank, while both Country 7 and Country 8 believed its performance to be excellent, Country 6, Country 9, Country 12 and Country 13 ranked the APO's performance as mediocre. With respect to performance as a catalyst, Country 8 and Country 16 believed the APO's performance to be excellent while Country 9 and Country 2 ranked it as mediocre. With respect to performance as regional adviser, Country 8 ranked the APO's performance as excellent while Country 9, Country 11 and Country 12 ranked its performance as poor. With respect to the APO's role as an institution builder, Country 8 ranked its performance as excellent while Country 9 and Country 12 ranked it as mediocre. Finally, with respect to its role as a clearinghouse for productivity information, Country 8, Country 14 and Country 16 ranked its performance as excellent while Country 9 ranked it as poor.

\section{Place Figures $4-8$}

Figure 9 shows the findings about the level of impact that NPO staff/CEO/directors attributed to the APO event or projects that they had been involved in. The findings indicate that stakeholders in Country 8 indicates the highest level of impact with a score of 5.3 and followed by stakeholders in Country 14, Country 16 and Country 4 with scores of 5.1, 5.0 and 5.0 respectively. In contrast, stakeholders in Country 15 indicated the lowest level of impact with a score of 3.4 followed by Country 9, Country 11 and Country 12 with scores of 3.6, 3.8 and 3.9 respectively. In the survey a score of 6 indicated excellent, 5-very good, 4 - good, 3 - mediocre, 2 - poor and 1 indicated very poor.

\section{Place Figure 9}

\section{Assessment of APO's operational performance}


The CEOs/directors of each of the NPOs were asked to provide a consensus opinion from their respective countries with respect to assessing the operational performance of the APO across five factors - 'leadership', 'strategic planning', 'customer focus', 'human resources', 'operations focus' and 'measurement, analysis and knowledge management.' The overall results indicate that human resources was ranked highest (4.1) followed by operations focus (3.9). All other factors scored 3.7. In the survey, a rank of 5 indicated very satisfied while 4 indicated satisfied and 3 indicated neither satisfied nor dissatisfied. A rank of 2 indicated dissatisfied while a rank of 1 indicated very dissatisfied. Therefore, across all the countries surveyed, the overall perception was that the APO's services were viewed positively.

\section{Impact of APO's Services on NPOs' Productivity Initiatives}

The CEOs/directors of each NPO were asked to assess the impact of 17 APO services on their own productivity initiatives. They were asked to rank the impact on a $\mathbf{1 - 6}$ likert scale with $\mathbf{1}$ signifying 'no impact' and $\mathbf{6}$ signifying 'very high impact' and $\mathbf{5}$ was 'high impact' while $\mathbf{4}$ was 'moderate impact. Scores of $\mathbf{3}$ and $\mathbf{2}$ represented 'low impact' and 'very low impact' respectively. The overall result across the 16 countries is shown in table 3 . It shows that all the APO's services studied in this research had a positive impact. The overall mean for each of the 17 services were within the range of moderate to high impact. In particular, training courses, technical expert services, development of demonstration companies/organizations and in-country programs/projects all had mean scores of 5.0 and this shows that they were viewed as high impact activities. The service with the lowest mean score was productivity research with a score of 4.2 .

Table 3: Impact of APO Services on NPO's Productivity Initiatives

\begin{tabular}{|l|c|}
\hline \multicolumn{1}{|c|}{ Service } & Overall Mean \\
\hline Training courses & $\mathbf{5 . 0}$ \\
\hline Technical expert services & $\mathbf{5 . 0}$ \\
\hline Development of demonstration companies / organizations & $\mathbf{5 . 0}$ \\
\hline In-country programs/projects & $\mathbf{5 . 0}$ \\
\hline Observational Study Missions & 4.9 \\
\hline Bilateral cooperation between NPO'S & $\mathbf{4 . 8}$ \\
\hline Institutional strengthening of NPO'S & 4.8 \\
\hline Workshops & 4.7 \\
\hline Expert Group Meetings & 4.6 \\
\hline Forums & 4.6 \\
\hline Multi-country programs/projects & 4.6 \\
\hline $\begin{array}{l}\text { Services to raise the visibility and importance of productivity and the contributions } \\
\text { of NPO'S }\end{array}$ & 4.6 \\
\hline Seminars & 4.5 \\
\hline E-learning courses & 4.5 \\
\hline $\begin{array}{l}\text { Centre of Excellence for Business Excellence (undertaken by SPRING Singapore on } \\
\text { behalf of APO) }\end{array}$ & 4.5 \\
\hline Conferences & 4.4 \\
\hline Productivity Research & 4.2 \\
\hline
\end{tabular}


The NPOs were also asked to provide information on their customers' preferences in terms of 74 productivity related services. From this list customers were asked which 10 were the most important to raise the performance of their own organisation. There were responses from 390 customers (a minimum of 20 customer responses per country was obtained. Of the services offered customers rated Training, Workshops and/or e-learning in the area of "Customer Focus - understanding customers, building customer relationships and managing customer complaints" as the most important with $43 \%$ indicating this in their selection of 10 services. Second, and third placed were Training, Workshops and/or e-learning in the areas of "Leadership - vision, values, developing leaders, ethics and governance" (41\%) and "Strategic Planning and Deployment - balanced scorecard and performance management" (39\%). Of note, was the finding that Training, workshops and/or e-learning activities in Strategic Planning and Deployment were provided by 13 of the 16 NPOs, whilst those in Customer Focus and Leadership were provided by 11 of the 16 NPOs. There are therefore significant gaps in the services that some of the NPOs provide and the services their customers require, and it is therefore recommended that the APO review whether these topics are adequately covered in the programs it provides to the NPOs. Table 3 shows that NPOs rate the APO's Training Courses as having a high impact (4.0), whereas their Workshops (3.7), Forums (3.6), Seminars (3.5) and E-Learning Courses (3.5) are all rated as having a moderate impact. The APO could use this information in the determination and design of future support services.

\section{Discussion}

The APO strives to play an important role in fostering productivity and development in its regions of influence. However, as the APO does not typically deal directly with individual organisations (but rather with its constituent NPO members) it is important to understand the perceptions of the leaders of the NPOs.

\section{Revisiting the Study Objectives}

The first objective of this study was to investigate NPO perceptions of the mission, vision and strategy of the APO. The study shows that, in general, leaders of the NPOs of the different countries are positive about the mission, vision and strategy of the APO. The second objective of the study was to investigate the key roles of the NPO and its level of performance. In general, the countries were positive about the key roles of the APO. However, perceptions about its current performance in those roles varied significantly. For example while Country 8, Country 14 and Country 16 felt the APO performed excellently as a clearing house for productivity information, Country 9 felt that it performed poorly. The third objective was to identify levels of satisfaction with the APO's operational performance. While the overall levels of performance were above average or quite high, some countries such as Country 2 , Country 8 , Country 16 and Country 14 were consistently more satisfied with the APO's performance when compared to countries such as Country 9, Country 12 and Country 15 which ranked the APO lower across almost all the operational areas.

\section{$\underline{\text { APO relationships with NPOs }}$}

The findings suggest a mixed perception of the APO by leaders of the different NPOs. Country 12 , in particular, ranked the APO lowest in terms of its mission, vision and strategic direction and therefore, it is not too surprising that it ranked the APO relatively lowly in terms of its key roles and performance. On the other hand, Country 2, Country 8 and Country 16 ranked the APO highly in 
terms of its vision, mission and strategic directions and followed this through with high rankings in terms of the APO's key roles and performance. Therefore, for these countries, there appears to be an association with their belief in the APO's overall direction and its ability to achieve key objectives. However, while countries like Country 1, Country 5 and Country 13 rated the APO's mission, vision and strategic direction relatively high, their perception of its current performance was more mixed.

The perception of these latter countries probably sums up the aggregated view of all the findings as thus. The APO has a mission, vision, strategic direction and key roles that its NPO membership is happy with but while its current performance is generally good, it does not match the levels of confidence and satisfaction with the former four factors. Therefore, the general perception is that the APO can perform better.

The results on the APO's activities suggest that the APO has been able to successfully identify and deploy activities which were each deemed to have a positive impact on the NPOs. This is an important result for the APO and the NPOs as it shows that the mission/vision/strategy of the APO as well as the productivity aspirations of its membership has been delivered by means of the 17 activities examined. Clearly, the success associated with these activities has played an influencing role in the positive overall assessment given to the APO by the NPOs.

\section{Improving Performance}

It is clear that while some NPOs are very happy with the NPO's current operations, others are less so. The suggestion is that the expectations and needs of the NPOs differ significantly. This may be as a result of different national priorities, cultures or levels of development. There also exists a great deal of difference between the NPOs in each country in a number of aspects such as years of APO membership, staff numbers, staff competencies and the level of government funding to name but a few. For example, the longest serving NPO was established in 1955 and joined the APO in 1961, whereas the shortest serving NPO has only existed since 2006 although the country joined the APO in 2004. Similarly, one NPO has 670 members of staff whilst another has 16 staff. Three NPOs insist that all their professional/technical staff have been educated at degree level or above, whilst two NPOs have $20 \%$ to $30 \%$ educated at degree level. Some NPOs received almost $100 \%$ government funding whilst others received no government funding. Finally, one NPO boasted 65 Training Rooms throughout their country whilst four had none. As a result, the expectations and needs of each country are very different, suggesting that the APO may not be able to fully satisfy all NPOs.

With respect to the APO's performance with regard to its role it is clear that the largest opportunity for improvement is as a regional advisor. It is recommended that the APO investigates this finding further to see whether or not a more tailored service is required for specific regions or whether it means the APO must play a greater mentoring or leadership role in some countries. It is also evident that current APO services which are tailored to specific countries such as Technical Expert Services and In-country programs/projects rated as having the most impact by NPOs.

Of the 17 services provided by the APO the following were considered by NPO members to equally have the highest impact; Training courses, Technical expert services, Development of demonstration companies / organizations and In-country programs/projects. The APO should consider providing additional resource for these services. The APO's "Productivity Research" was considered by some distance to have the lowest impact of 17 services with it averaging as having slightly higher than a 
"moderate impact". The APO should investigate the level of resource invested in this activity and whether it should be reduced or consider how APO members can obtain more value from this service.

\section{Conclusion}

This study set out to investigate the perceptions of Asian NPOs about the APO. It has shown that, in general, the NPOs are pleased with the mission, vision, strategic direction and key roles of the APO. However, the study has also indicated that while the APO's performance is positively viewed, there is a consensus that its performance can be improved. The study has also shown that while some countries are consistently satisfied with the APO, others are less so. With respect to areas for improvement, the study has indicated that the APO should review how it undertakes its role as a regional advisor.

\section{Study Implications}

The study has important academic and industry implications. Firstly, for the APO, the study implies a need to understand the varying expectations of its NPO members and to provide tailored support. Secondly, for the different NPOs, there is a need to work more closely with the APO in order to obtain the benefits that they desire. It is clear that some countries are significantly more satisfied than others and therefore it is up-to the affected NPOs and APO to review how their association can result in greater benefits. Thirdly, the study has implications for other regions of the world. For regions with pan-national productivity organisations such as the APO, there is a need to understand the effectiveness of such organisations. On the other hand, for regions without such organisations, it may be worth exploring the possibility of setting up a similar organisation as it is clear from the study that NPOs can benefit from such pan-national organisations. NPO benefits will, in turn, translate to productivity benefits for individual firms and boost national development.

For academia, there is a need to understand how the relationships between the individual NPOs and the APO affect the performance of the NPOs and the support that they, in turn, provide to individual organisations in their countries. In addition, there needs to be better understanding of how organisations such as the APO and the NPOs facilitate improvements in national productivity.

Finally, the study's limitations are provided. First, while the study covers many Asian countries, the views of the most advanced countries such as Singapore, Korea and Japan are not represented and so it is not possible to learn from their perceptions. 
References

Asian Productivity Organization (APO). (2015). APO Annual Report 2014. Asian Productivity Organization, Tokyo.

Burgess, T.F. (1990),"A Review of Productivity", Work Study, Vol. 39 No. 1, pp. 6 - 10

Ho, S.K.M (2010),"Integrated lean TQM model for global sustainability and competitiveness", The TQM Journal, Vol. 22 No. 2, pp. 143 - 158

Jain, S.K. and Ahuja, I.S. (2012),"An evaluation of ISO 9000 initiatives in Indian industry for enhanced manufacturing performance", International Journal of Productivity and Performance Management, Vol. 61 No 7, pp. $778-804$

Kocer, R.G. (2014),"Can productivity be socially embedded? Reflections on some productivity measures of 2000s", International Journal of Productivity and Performance Management, Vol. 63 No. 3, pp. $354-369$

Mathur, A., Mittal, M.L. and Dangayach, G.S. (2012) "Improving productivity in Indian SMEs", Production Planning \& Control: The Management of Operations, Vol. 23 No.10/11, pp. 754-768

Mohanty, R.P. (1988),"Factors Affecting Productivity: Perceptions of Indian Managers", Industrial Management \& Data Systems, Vol. 88 No. 7/8, pp. 21 - 26

Peskircioglu, N. (2008),"MPM's productivity improvement project approach in provinces", International Journal of Productivity and Performance Management, Vol. 57 No. 6, pp. 440 448

Sakurai, K. (1986),"Japanese Worker Attitudes: A Key Factor in Productivity", International Journal of Operations \& Production Management, Vol. 6 No. 1, pp. 42 - 53

Sarwar S.Z., Ishaque A., Ehsan, N., Pirzada, D.S. and Nasir, Z.M. (2012),"Identifying productivity blemishes in Pakistan automotive industry: a case study", International Journal of Productivity and Performance Management, Vol. 61 No. 2, pp. 173 - 193

Savery, L.K. (1998),"Management and productivity increases", Journal of Management Development, Vol. 17 No. 1, pp. 68 - 74

Shurchuluu,P. (2002),"National productivity and competitive strategies for the new millennium", Integrated Manufacturing Systems, Vol. 13 No. 6, pp. $408-414$

Stainer, A. (1995),"Productivity management: the Japanese experience", Management Decision, Vol. 33 No. 8, pp. $4-12$

Teng, H.S.S. (2014),"Qualitative productivity analysis: does a non-financial measurement model exist?", International Journal of Productivity and Performance Management, Vol. 63 No. 2, pp. $250-256$

Tuttle, T. and Heap, J. (2007),"Green productivity: moving the agenda", International Journal of Productivity and Performance Management, Vol. 57 No. 1, pp. 93 - 106 


\section{Figures}

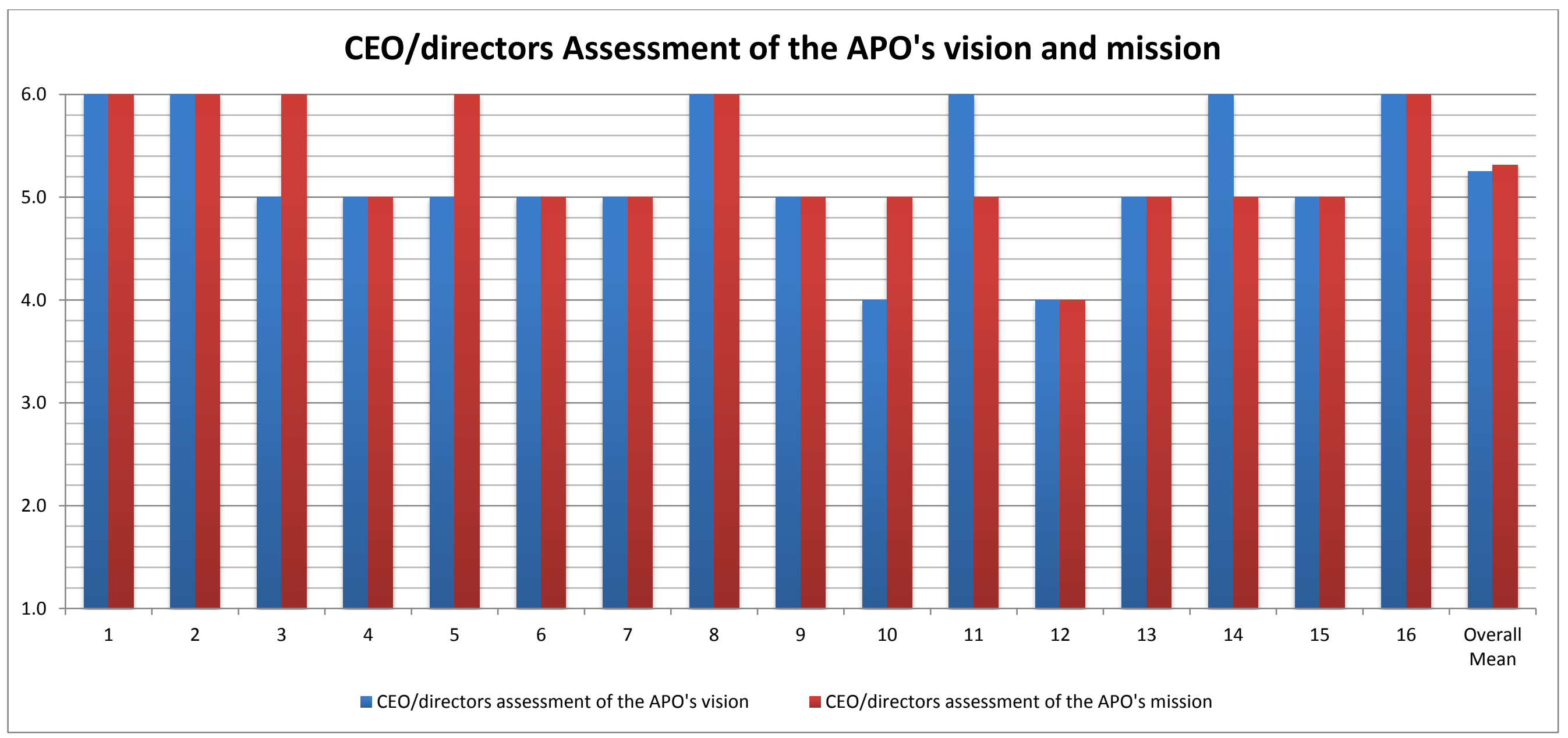

Figure 1: CEO/directors assessment of the APO's vision and Mission 


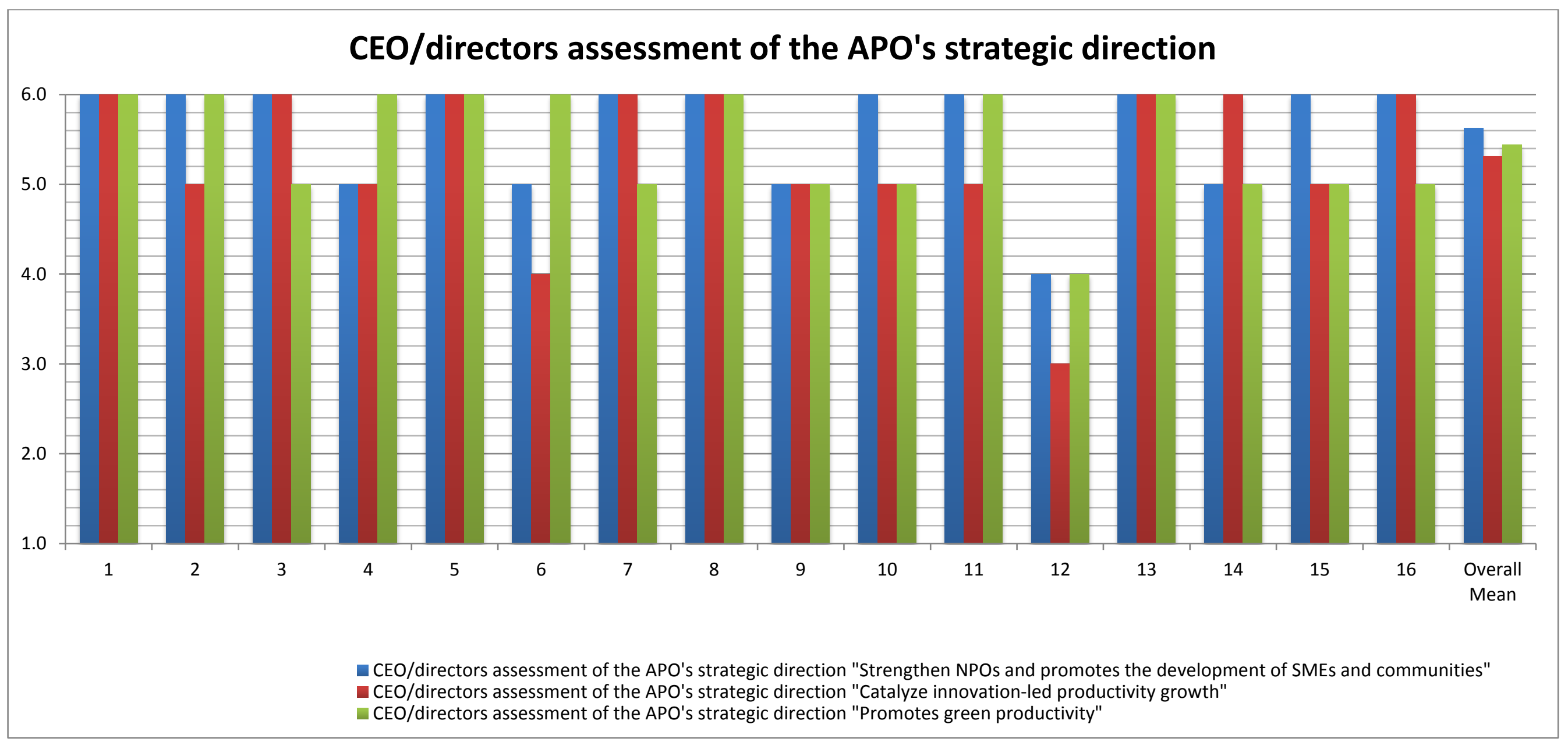

Figure 2: CEO/director's assessment of the APO's strategic direction 


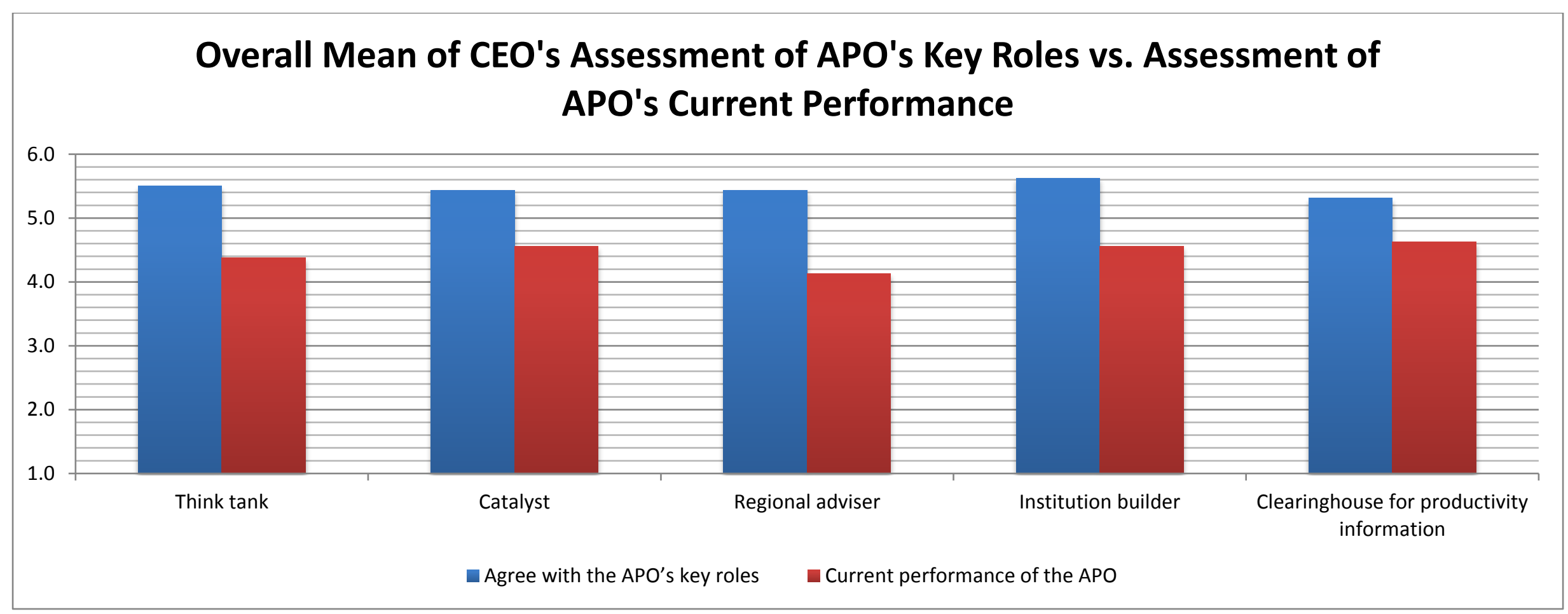

Figure 3: CEOs Assessment of APO's Key Roles Vs. their Assessment of APO's Current Performance (For APO's Key Roles: 6 refers to Strongly Agree, 5 refers to Agree, 4 refers to Tend to Agree, 3 refers to Tend to Disagree, 2 refers to Disagree and 1 refers to Strongly Disagree. For APO's Current Performance: 6 refers to Excellent, 5 refers to Very Good, 4 refers to Good, 3 refers to Mediocre, 2 refers to Poor and 1 refers to Very Poor). 


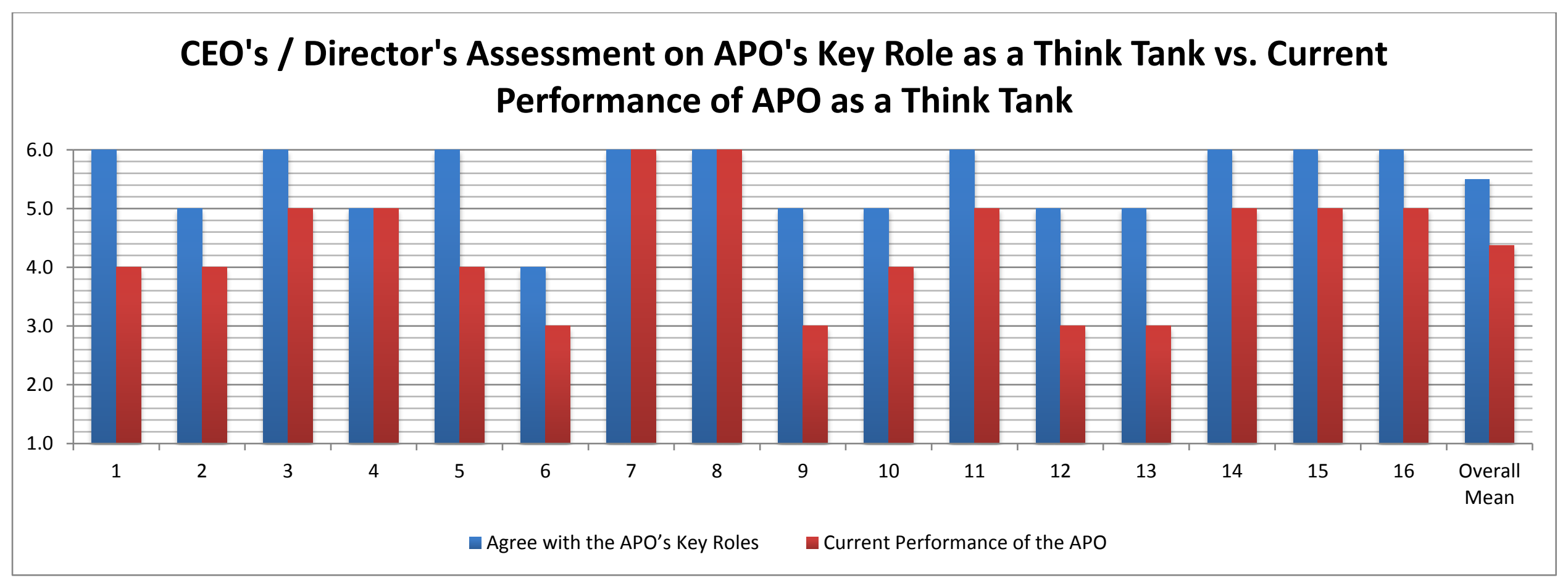

Figure 4: CEOs Assessment of APO's Key Role as a Think Tank vs. Current Performance of APO as a Think Tank (For APO's Key Roles: 6 refers to Strongly Agree, 5 refers to Agree, 4 refers to Tend to Agree, 3 refers to Tend to Disagree, 2 refers to Disagree and 1 refers to Strongly Disagree. For APO's Current Performance: 6 refers to Excellent, 5 refers to Very Good, 4 refers to Good, 3 refers to Mediocre, 2 refers to Poor and 1 refers to Very Poor). 


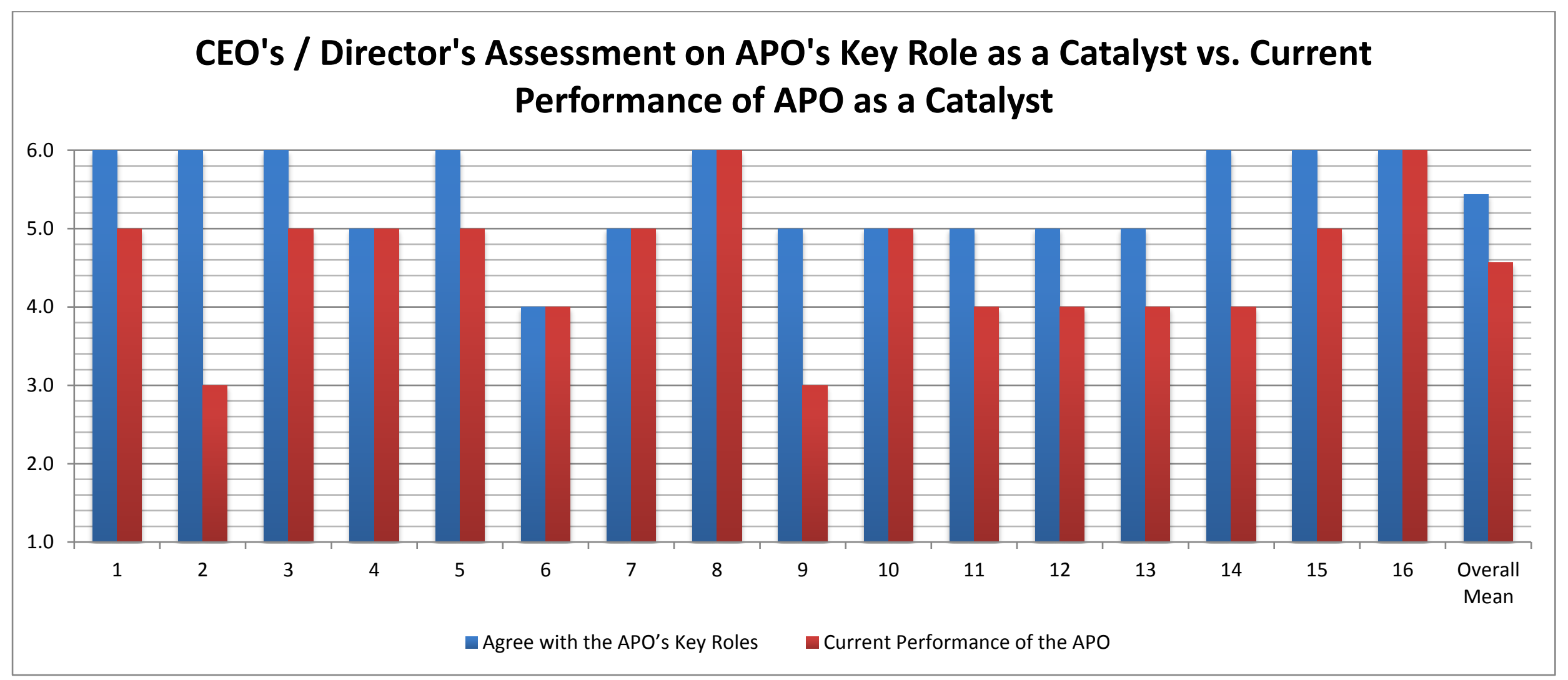

Figure 5: CEOs Assessment of APO's Key Role as a Catalyst vs. Current Performance of APO as a Catalyst (For APO's Key Roles: 6 refers to Strongly Agree, 5 refers to Agree, 4 refers to Tend to Agree, 3 refers to Tend to Disagree, 2 refers to Disagree and 1 refers to Strongly Disagree. For APO's Current Performance: 6 refers to Excellent, 5 refers to Very Good, 4 refers to Good, 3 refers to Mediocre, 2 refers to Poor and 1 refers to Very Poor). 


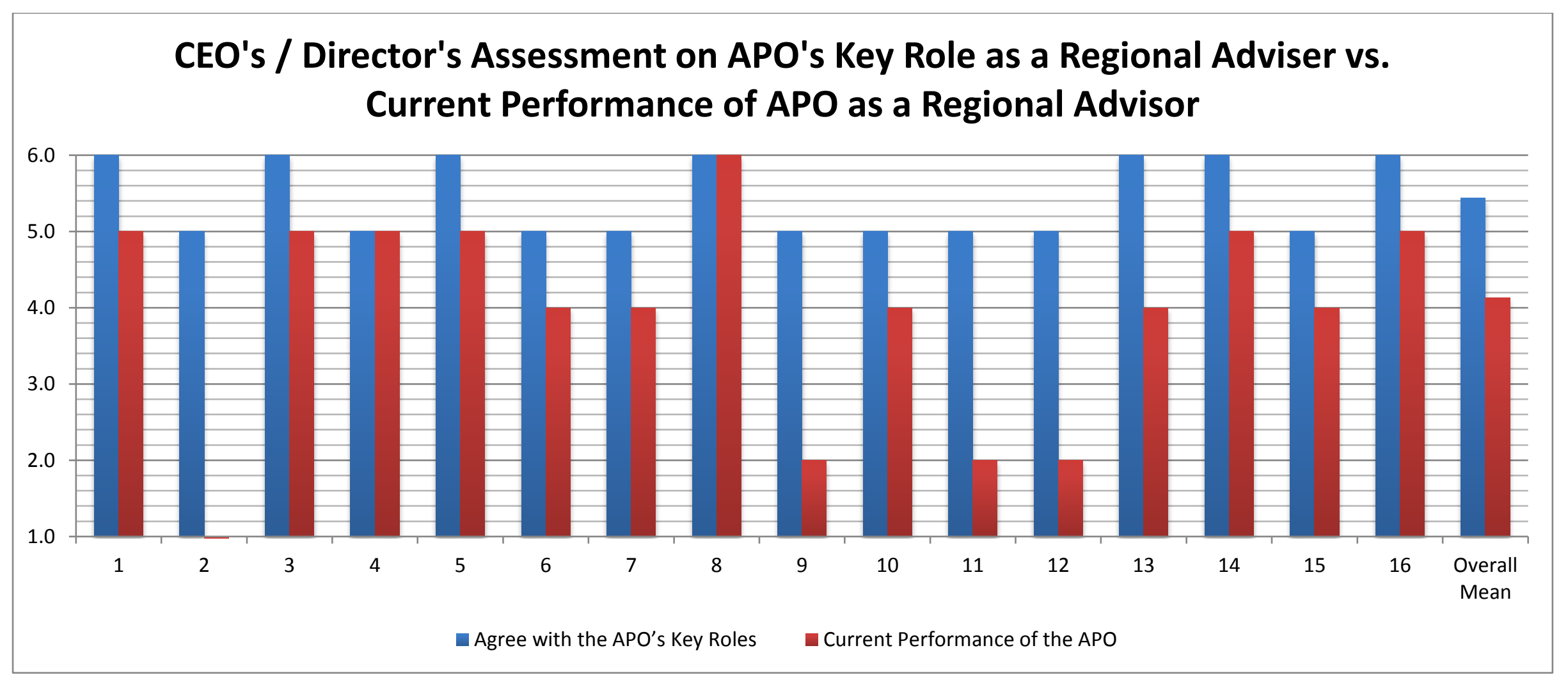

Figure 6: CEOs Assessment of APO's Key Role as a Regional Adviser vs. Current Performance of APO as a Regional Adviser (For APO's Key Roles: 6 refers to Strongly Agree, 5 refers to Agree, 4 refers to Tend to Agree, 3 refers to Tend to Disagree, 2 refers to Disagree and 1 refers to Strongly Disagree. For APO's Current Performance: 6 refers to Excellent, 5 refers to Very Good, 4 refers to Good, 3 refers to Mediocre, 2 refers to Poor and 1 refers to Very Poor). 


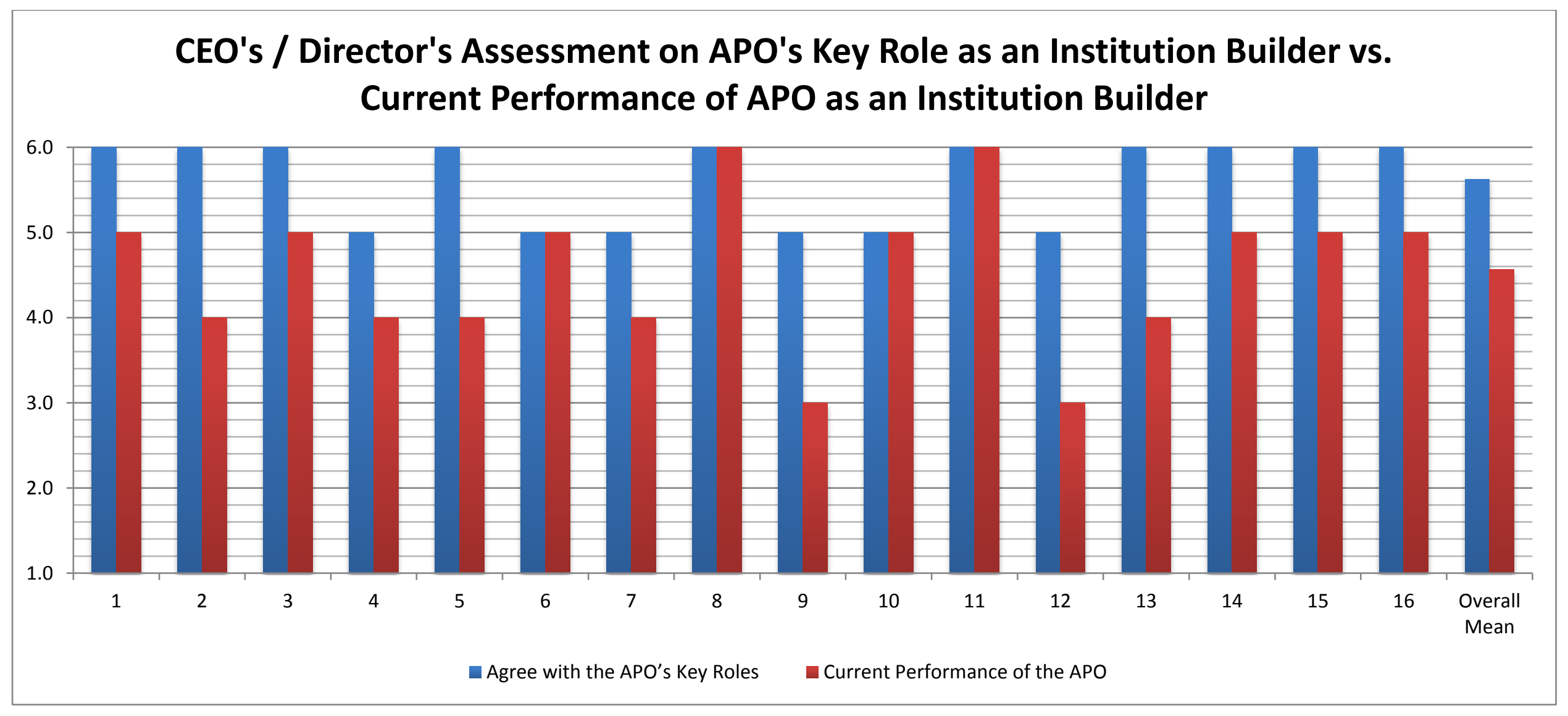

Figure 7: CEOs Assessment of APO's Key Role as an Institution Builder vs. Current Performance of APO as an Institution Builder (For APO's Key Roles: 6 refers to Strongly Agree, 5 refers to Agree, 4 refers to Tend to Agree, 3 refers to Tend to Disagree, 2 refers to Disagree and 1 refers to Strongly Disagree. For APO's Current Performance: 6 refers to Excellent, 5 refers to Very Good, 4 refers to Good, 3 refers to Mediocre, 2 refers to Poor and 1 refers to Very Poor). 


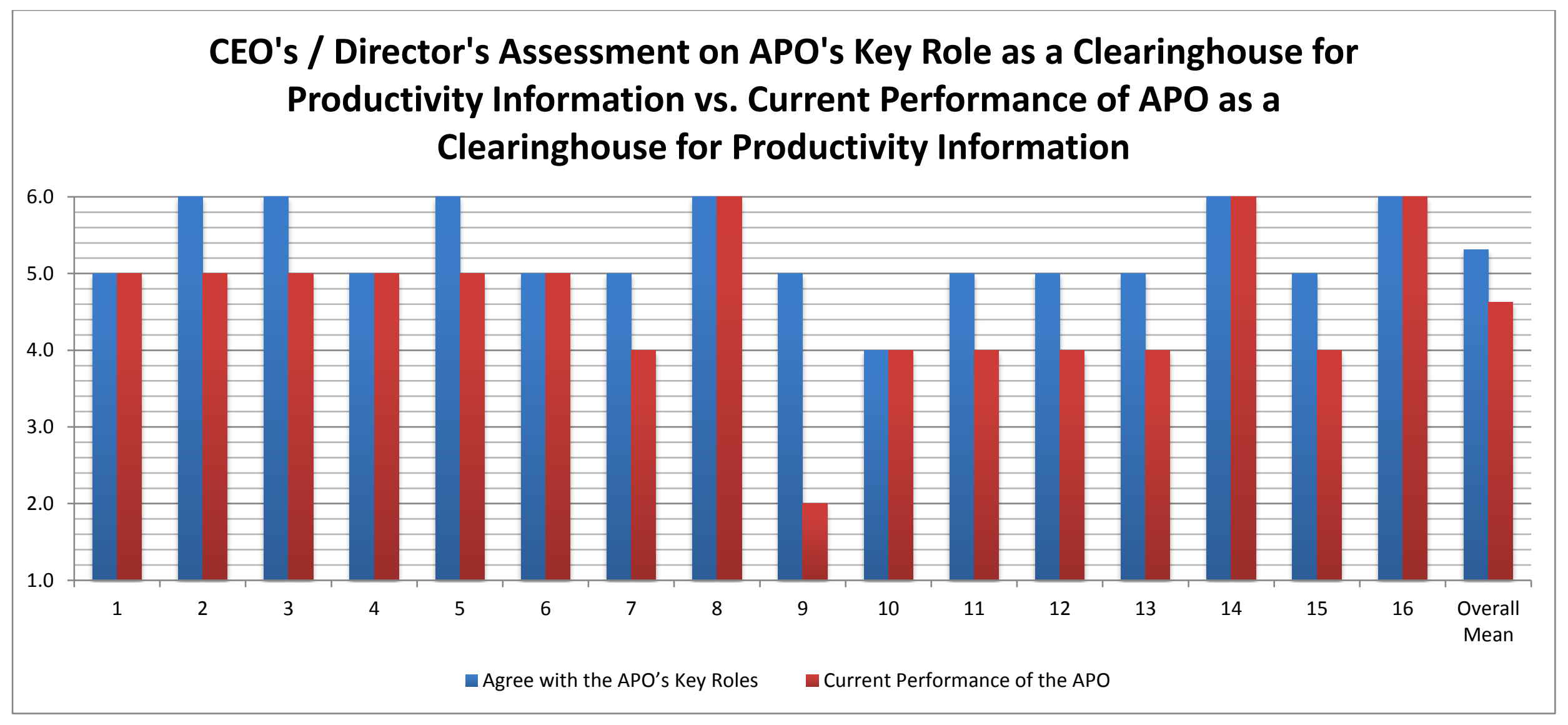

Figure 8: CEOs Assessment of APO's Key Role as a Clearinghouse for Productivity Information vs. Current Performance of APO as a Clearinghouse for Productivity Information (For APO's Key Roles: 6 refers to Strongly Agree, 5 refers to Agree, 4 refers to Tend to Agree, 3 refers to Tend to Disagree, 2 refers to Disagree and 1 refers to Strongly Disagree. For APO's Current Performance: 6 refers to Excellent, 5 refers to Very Good, 4 refers to Good, 3 refers to Mediocre, 2 refers to Poor and 1 refers to Very Poor). 


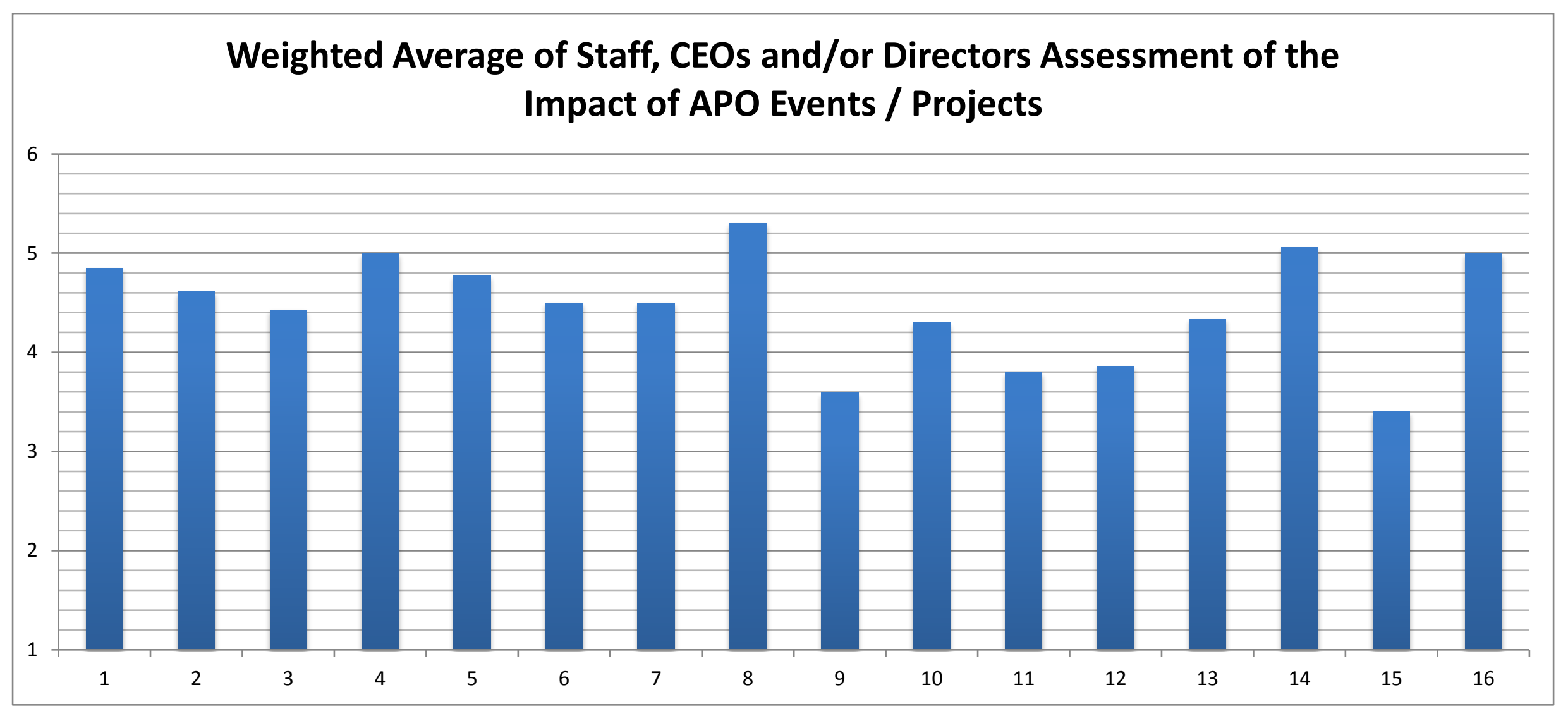

Figure 9: Staff Perception of Impact of APO Events / Projects 